\title{
Usefulness of glycated albumin as a predictor of mortality in chronic hemodialysis patients with diabetes: a multi-center, prospective cohort study
}

Ko Hanai ${ }^{1}$, Makoto Akamatsu², Aki Fujimori ${ }^{3}$, Harumichi Higashi ${ }^{4}$, Yumiko Horie ${ }^{5}$, Yoshiaki Itaya ${ }^{6}$, Minoru Ito ${ }^{7}$, Tomoko Kanamaru ${ }^{8}$, Hiroshi Kawaguchi ${ }^{9}$, Kan Kikuchi ${ }^{10}$, Hideo Kobayashi ${ }^{11}$, Machiko Komatsu ${ }^{12}$, Takao Kubota ${ }^{13}$, Kenichi Kudo ${ }^{14}$, Satoshi Kurihara ${ }^{15}$, Ikuto Masakane ${ }^{7}$, Junichiro Mera ${ }^{16}$, Sonoo Mizuiri ${ }^{17}$, Kimiko Moriyama ${ }^{18}$, Junichiro Nagasawa ${ }^{19}$, Sumiyo Nagata ${ }^{20}$, Yoshihiko Nakagawa ${ }^{21}$, Satoshi Nakazato ${ }^{22}$, Takahiro Nishi ${ }^{23}$, Yoshihiko Noma ${ }^{12}$, Naoyuki Odaguchi ${ }^{22}$, Senji Okuno ${ }^{24}$, Shiwori Osada ${ }^{25}$, Hisashi Ozasa ${ }^{26}$, Sumihiko Sato ${ }^{27}$, Tokihiko Sawada $^{28}$, Tsuyako Shimajiri $^{22}$, Yukiko Shimamoto ${ }^{29}$, Masakazu Suda ${ }^{30}$, Toshihide Suzuki ${ }^{31}$, Hiromichi Suzuki ${ }^{32}$, Maki Takahashi ${ }^{33}$, Hajime Takahashi ${ }^{34}$, Toshimasa Takahashi ${ }^{35}$, Yoshihiro Takebayashi ${ }^{34}$, Masanobu Takeda ${ }^{5}$, Hiroyuki Tamura ${ }^{28}$, Yoshiko Tanaka ${ }^{36}$, Sohei Tokunaka ${ }^{37}$, Shinji Tsuda ${ }^{38}$, Mio Ueda ${ }^{37}$, Ichiro Yamaguchi ${ }^{19}$, Hirohisa Yamamoto ${ }^{39}$, Yasuko Uchigata ${ }^{1}$ and Tetsuya Babazono ${ }^{1 *}$

\section{Abstract}

Background: The association of glycated albumin (GA) with mortality is unclear in chronic hemodialysis patients with diabetes. We investigated the usefulness of GA by comparing it with hemoglobin A1c $(\mathrm{HbA1c})$ in this patient population.

Research design and methods: This was a multi-center, prospective cohort study of 841 Japanese chronic hemodialysis patients with diabetes. There were 235 women and 606 men included, with a mean age of 64 years. The primary and secondary endpoints were the incidence of all-cause and cause-specific mortality, respectively. The hazard ratios of GA and $\mathrm{HbA1c}$ for the endpoints were estimated using the values at baseline and during the study period.

Results: During the mean follow-up period of 3.1 years, there were 184 deceased cases, in which 30 and 154 resulted from atherosclerotic cardiovascular disease (ASCVD) and non-ASCVD, respectively. The hazard ratio for a $1 \%$ increase in GA was 1.033 (95\% confidence interval 1.006-1.060, $p=0.017$ ) for all-cause mortality with a statistical significance when GA was treated as a time dependent variable, but not when the baseline levels or the mean levels during the followup period were used in the analysis ( $p=0.815$ and 0.517 , respectively). GA was a significant predictor for ASCVD-related mortality in the above 3 models, but was not for non-ASCVD mortality. Higher levels of $\mathrm{HbA1c}$ were only associated with ASCVD-related mortality when HbA1c was treated as a time-dependent variable.

(Continued on next page)

\footnotetext{
* Correspondence: babazono.dmc@twmu.ac.jp

'Diabetes Center, Tokyo Women's Medical University School of Medicine, 8-1 Kawada-cho, Shinjuku-ku, Tokyo 162-8666, Japan

Full list of author information is available at the end of the article
}

(C) The Author(s). 2020 Open Access This article is licensed under a Creative Commons Attribution 4.0 International License, which permits use, sharing, adaptation, distribution and reproduction in any medium or format, as long as you give appropriate credit to the original author(s) and the source, provide a link to the Creative Commons licence, and indicate if changes were made. The images or other third party material in this article are included in the article's Creative Commons licence, unless indicated otherwise in a credit line to the material. If material is not included in the article's Creative Commons licence and your intended use is not permitted by statutory regulation or exceeds the permitted use, you will need to obtain permission directly from the copyright holder. To view a copy of this licence, visit http://creativecommons.org/licenses/by/4.0/ The Creative Commons Public Domain Dedication waiver (http://creativecommons.org/publicdomain/zero/1.0/) applies to the data made available in this article, unless otherwise stated in a credit line to the data. 
(Continued from previous page)

Conclusions: GA may be useful compared to HbA1c for predicting all-cause and ASCVD-related mortality in Japanese patients with diabetes undergoing chronic hemodialysis.

\section{Background}

The importance of glycemic control for preventing the development and progression of microvascular complications in patients with diabetes has been well established through substantial randomized controlled trials [1]; nonetheless, the role in these patients undergoing chronic dialysis remains unclear, due to a lack of the randomized controlled trials in this patient population. Previous cohort studies have reported that higher levels of hemoglobin A1c (HbA1c), the gold standard indicators of glycemic control, predicted all-cause and cardiovascular mortality in patients with diabetes undergoing chronic hemodialysis [2-4]. However, in patients with advanced stage of diabetic kidney disease (DKD), HbA1c values are underestimated due to unpredictable changes in the survival time of erythrocyte, leading to the unreliability of the HbA1c values $[5,6]$.

Glycated albumin (GA), reflecting average glucose levels during the preceding 2 to 3 weeks, has been shown to be preferable to HbA1c for the assessment of glycemic control in chronic hemodialysis patients with diabetes because GA levels are not affected by the life span of erythrocytes [5-7]. To date, few large cohort studies have reported an association between GA and mortality in such patient population $[8,9]$; moreover, these studies were retrospectively designed and did not evaluate GA values during the study period, although these levels can vary over time. Here, we prospectively investigated the usefulness of GA, assessed based on both baseline and follow-up values, with respect to mortality by comparing it with HbA1c in Japanese chronic hemodialysis patients with diabetes.

\section{Materials and methods Study design and participants}

This multi-center, prospective cohort study (UMIN clinical trial registry number: UMIN000009036) was designed in adherence to the Declaration of Helsinki, and was approved by the Ethics Committee of Tokyo Women's Medical University School of Medicine. All patients provided written informed consent. A total of 972 adult patients with diabetes receiving chronic hemodialysis at 39 Japanese medical institutions were recruited between April 2013 and August 2015 for the present study. At baseline, patients with a dialysis vintage less than 6 months or unknown $(n=40)$ were excluded. This was because previous large cohort studies of chronic hemodialysis patients have shown that the effects of glycemic control on mortality with short dialysis vintage, especially of less than 6 months, were noticeably different from those with the longer vintage $[4,10]$. Patients who had malignant disease $(n=22)$, acute severe infection $(n=16)$, or who had missing baseline profile values $(n=6)$ were excluded. Patients with liver cirrhosis $(n=7)$ or dysthyroidism $(n=40)$ were also excluded because these conditions may impact GA $[11,12]$. Overall, data obtained from 841 participants were analyzed in the present study (Supplementary Figure 1).

\section{Measurements}

Laboratory data were collected before each dialysis session in 808 patients. For the remaining 33 patients, random spot blood samples were taken when they visited Tokyo Women's Medical University School of Medicine for the purpose of glycemic control. The samples were analyzed at a central laboratory. GA, HbA1c, and glucose levels, most of them were sampled postprandially, were determined by an enzymatic method using the following: Lucica GA-L, Asahi Kasei Pharma Co., Ltd., Tokyo, Japan; MetaboLead HbA1c, Kyowa Medex Co., Ltd., Tokyo, Japan; and IatroLQ GLU, Unitika Co., Ltd., Osaka, Japan; respectively. GA, HbA1c, and glucose levels were measured at baseline and every 6 months thereafter during the follow-up period. Other laboratory data were measured at baseline. Information on dialysis vintage, type of diabetes, medication, atherosclerotic cardiovascular disease (ASCVD), smoking status, body mass index (BMI), and blood pressure at baseline were obtained from medical records at each institution.

\section{Endpoints and follow-up}

The primary and secondary endpoints were the incidence of all-cause and cause-specific mortality, respectively, the latter of which was classified into ASCVD-related and non-ASCVD-related mortality. Ischemic heart diseases including acute myocardial infarction, cerebral hemorrhage, and cerebral infarction were defined as causes of ASCVDrelated death. Patients were censored when they underwent kidney transplantation, transferred to a different medical institution, lost to follow-up, or at the administrative censoring date (December 31, 2017).

\section{Statistical analysis}

All analyses were completed using the SAS version 9.4 (SAS Institute Inc., Cary, NC, USA). Continuous data were expressed as the arithmetic mean \pm standard deviation (SD), or median (interquartile range, IQR), as appropriate. Categorical data were expressed as number (\%). A linear correlation between 2 variables was assessed using the Pearson correlation coefficient. A 
cumulative incidence of the endpoints was estimated using the Kaplan-Meier method. The multivariate Cox proportional hazards models were used to estimate hazard ratios and 95\% confidence intervals (CIs). Possible nonlinear associations were examined using the multivariable-adjusted restricted cubic spline model [13], with the 3 knots placed at the 10th, 50th, and 90th percentile levels. A comparison regarding the predictability of GA and HbA1c levels for time to the endpoints was assessed using the Uno's overall C-statistics [14]. Three sets of models were used to calculate the hazard ratios (and 95\% CI) of GA and HbA1c levels for the endpoints: model 1, in which the hazard ratios were estimated using baseline GA or HbA1c values; model 2, which used mean values of GA or HbA1c during the follow-up period; and model 3, in which GA or HbA1c values during the follow-up period were treated as time-dependent variables. All hazard ratios were adjusted by the following variables: age, sex, dialysis vintage, type of diabetes, use of angiotensin-converting enzyme inhibitors or angiotensin II receptor blockers, history of ASCVD, BMI, systolic blood pressure, hemoglobin, serum albumin, corrected calcium, phosphate, and non-highdensity lipoprotein cholesterol. Original clinical factors used for the calculation of the overall C-statistics consisted of the above 13 variables. Variation inflation factors (VIF) were calculated to check the multicollinearity of the 13 variables; the values greater than 10 indicate severe multicollinearity [15], and all VIFs among the 13 variables were less than 2 . The measurements of GA and HbA1c in 118 patients were partly missed after the study began. The imputation of the missing data was not conducted and only available data during the periods were used in the analyses. A two-tailed $p$ value less than 0.05 was considered significant.

We conducted several sensitivity analyses as follows. First, we tested whether there are differences in the effects of GA levels on the endpoints depending on the serum levels of albumin. Second, we used the Fine and Gray subdistribution hazards model, considering the presence of competing risks [16, 17]. In the present study, non-ASCVD-related death was treated as a competing risk in the analysis examining time to ASCVDrelated death, and vice versa. Third, we made a model added diabetes therapy as covariates. Finally, we analyzed a model added levels of logarithmically transformed high-sensitivity C-reactive protein, closely associated with mortality in dialysis patients [18].

\section{Results}

Baseline characteristics

Of the 841 patients studied, there were 235 women and 606 men, with a mean $( \pm S D)$ age of $64 \pm 12$ years. Median (IQR) dialysis vintage was 4.5 years (2.4-7.9 years).
Mean values of GA and $\mathrm{HbA1c}$ at baseline were $21.4 \pm$ $5.0 \%$ and $6.4 \pm 1.1 \%$, respectively. There was a positive and significant association between GA and HbA1c $(r=$ 0.705, $p<0.001)$. Glucose levels also had a significant positive association with GA $(r=0.419, p<0.001)$ and HbA1c levels $(r=0.390, p<0.001)$, respectively. Other clinical characteristics and laboratory data are presented in Table 1.

\section{Association of $\mathrm{GA}$ and $\mathrm{HbA} 1 \mathrm{c}$ with mortality}

During the mean $( \pm \mathrm{SD})$ follow-up period of $3.1 \pm 1.3$ years, there were 184 deceased cases, in which 30 and 154 resulted from ASCVD and non-ASCVD, respectively (Fig. 1). The details of death from ASCVD were ischemic heart diseases in 12 patients and stroke in the other 18 patients. These from non-ASCVD were heart failure in 44 patients, infection in 23 patients, cancer in 16 patients, other causes in 30 patients, and unknown causes in the other 41 patients. Five patients underwent kidney transplantation, 143 were transferred to another institution, and 17 were lost to follow-up. As shown in Table 2 , the hazard ratio for a $1 \%$ increase in GA was 1.033 (95\% CI 1.006-1.060, $p=0.017$ ) for all-cause mortality, with a statistical significance in the analysis treating GA as a time dependent variables (model 3). GA was a significant predictor for ASCVD-related mortality in all 3 models, but was not for non-ASCVD-related mortality. Higher levels of HbA1c were only associated with ASCVD-related mortality in model 3; meanwhile, the lower levels had a significant association with nonASCVD-related mortality in the analysis using baseline HbA1c levels (model 1).

Next, we verified whether there is nonlinearity in the associations of GA and HbA1c with the time to reach the endpoints. The nonlinear association was rejected in all analyses using baseline GA and HbA1c values (Fig. 2 ). In the analyses using the mean values during the follow-up period, the results were not changed (Supplementary Figure 2).

Finally, we compared the predictability of GA and HbA1c for each endpoint (Table 3). When adding GA or $\mathrm{HbA} 1 \mathrm{c}$ values to the 13 original clinical factors, there was no significant improvement in the overall Cstatistics in any analysis. The $\mathrm{C}$-statistics of original factors plus GA were not significantly different from those adding HbA1c in any analysis (Table 3).

\section{Sensitivity analyses}

There was no interaction between albumin and GA levels with respect to the endpoints in any analysis (Supplementary Tables 1 ). When patients were classified into 2 groups by the median of serum albumin levels $(3.6 \mathrm{~g} /$ $\mathrm{dL}$ ), similar results to the above were obtained (Supplementary Tables 1). In the Fine and Gray subdistribution 
Table 1 Baseline demographic and laboratory data

\begin{tabular}{|c|c|}
\hline & Overall $(n=841)$ \\
\hline Age & $64 \pm 11$ years \\
\hline Men & $606(72.1 \%)$ \\
\hline Dialysis vintage & 4.5 years $(2.4-7.9)$ \\
\hline Type 1 diabetes & 75 (8.9\%) \\
\hline \multicolumn{2}{|l|}{ Diabetes therapy } \\
\hline Insulin & $344(40.9 \%)$ \\
\hline Other medication & $369(43.9 \%)$ \\
\hline ACE inhibitors or ARBs & $552(65.6 \%)$ \\
\hline Other antihypertensive drugs & $600(71.3 \%)$ \\
\hline Statins & $272(32.3 \%)$ \\
\hline History of ASCVD & $333(39.6 \%)$ \\
\hline Current smoker & $168(20.0 \%)$ \\
\hline Body mass index & $23.5 \pm 4.0 \mathrm{~kg} / \mathrm{m}^{2}$ \\
\hline SBP & $154 \pm 23 \mathrm{mmHg}$ \\
\hline DBP & $78 \pm 13 \mathrm{mmHg}$ \\
\hline \multicolumn{2}{|l|}{ Laboratory data } \\
\hline GA & $21.4 \pm 5.0 \%$ \\
\hline $\mathrm{HbA1c}$ & $6.4 \pm 1.1 \%$ \\
\hline Glucose & $145 \pm 55 \mathrm{mg} / \mathrm{dL}$ \\
\hline Hemoglobin & $10.8 \pm 1.1 \mathrm{~g} / \mathrm{dL}$ \\
\hline Albumin & $3.6 \pm 0.3 \mathrm{~g} / \mathrm{dL}$ \\
\hline Urea nitrogen & $59.3 \pm 15.2 \mathrm{mg} / \mathrm{dL}$ \\
\hline Creatinine & $10.5 \pm 2.6 \mathrm{mg} / \mathrm{dL}$ \\
\hline Potassium & $4.9 \pm 0.7 \mathrm{mEq} / \mathrm{L}$ \\
\hline Corrected calcium & $9.5 \pm 0.7 \mathrm{mg} / \mathrm{dL}$ \\
\hline Phosphate & $5.6 \pm 1.4 \mathrm{mg} / \mathrm{dL}$ \\
\hline HDL cholesterol & $45 \pm 15 \mathrm{mg} / \mathrm{dL}$ \\
\hline Non-HDL cholesterol & $109 \pm 32 \mathrm{mg} / \mathrm{dL}$ \\
\hline
\end{tabular}

Data are expressed as mean (standard deviation), median (interquartile range), or number (percentage)

$A C E$ angiotensin-converting enzyme, ARBs angiotensin receptor blockers,

$A S C V D$ atherosclerotic cardiovascular disease, $S B P$ systolic blood pressure, $D B P$ diastolic blood pressure, GA glycated albumin, HbA1c hemoglobin A1c, HDL high-density lipoprotein

hazards models, similar findings to the above were obtained (Supplementary Tables 2). In models added diabetes therapy or levels of logarithmically transformed high-sensitivity $\mathrm{C}$-reactive protein, similar results were obtained (Supplementary Tables 3 and 4).

\section{Discussion}

In this prospective cohort study, we have shown the usefulness of GA, assessed based on both baseline and follow-up values, for predicting all-cause and ASCVDrelated mortality in chronic hemodialysis patients with diabetes. The robustness of this finding was strengthened by conducting sensitivity analyses. Meanwhile, higher levels of HbA1c were only associated with

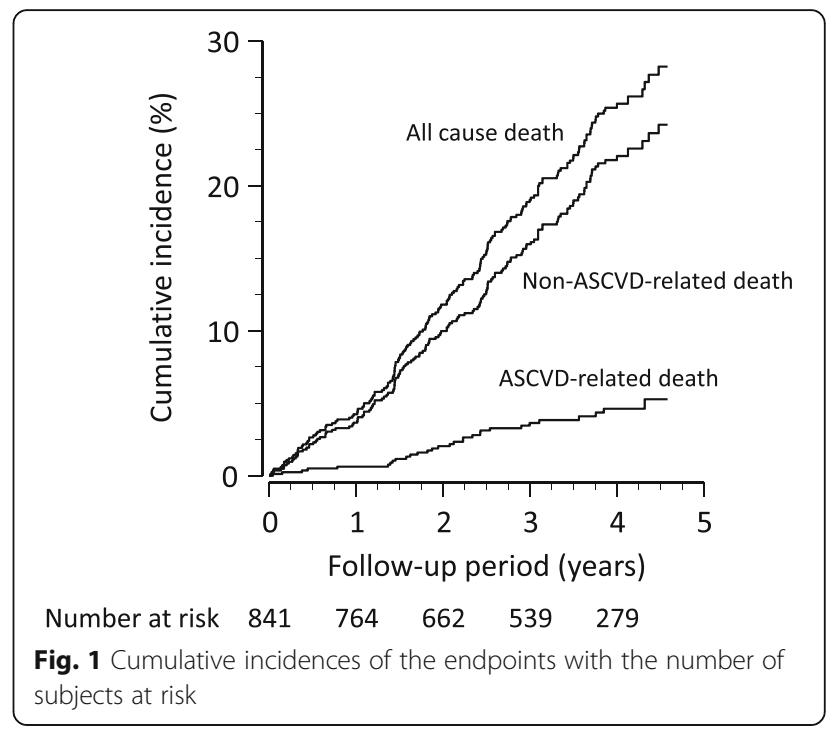

ASCVD-related mortality when treated as a timedependent variable, suggesting that GA is a preferable predictor for mortality compared to HbA1c in chronic hemodialysis patients with diabetes.

In the present study, GA levels at baseline were not associated with all-cause mortality, unlike those assessed as time-dependent variables, which was inconsistent with previous reports $[8,9,19,20]$. It is considered that the Cox regression model with time-dependent variables estimates the short-time effects of exposures, while that with baseline variables estimates the long-time effects $[21,22]$. Therefore, the present findings may suggest that short-term glycemic control has effects on mortality in chronic hemodialysis patients with diabetes, consistent with the present results showing no association of mean GA values during the follow-up period with allcause mortality. A large retrospective cohort study in a similar patient population from Japan showed a significant association between increased GA levels at baseline and all-cause mortality over a short follow-up duration of 1 year [9], although the difference from the present findings may simply be explained by the sample size. Another retrospective study with the longer follow-up periods of 4 years using the German Diabetes and Dialysis Study cohort showed that higher levels of GA at baseline were a significant predictor for all-cause mortality [8]. However, the incidence of cardiovascular mortality in chronic hemodialysis patients in Western countries is obviously higher than that in Japan [23-25]. In the present study, higher levels of GA were associated with ASCVD-related mortality in all models; therefore, the difference in the incidence of cardiovascular disease as the cause of death might explain the inconsistency between the German Diabetes and Dialysis Study and present study. 
Table 2 Hazard ratio of $1 \%$ increase in GA and HbA1c levels for each endpoint

\begin{tabular}{|c|c|c|c|c|c|}
\hline \multirow[b]{2}{*}{ Cause of death } & \multicolumn{3}{|l|}{$\mathrm{GA}$} & \multicolumn{2}{|l|}{$\mathrm{HbA1c}$} \\
\hline & & Hazard ratio $(95 \% \mathrm{Cl})$ & $p$ value & Hazard ratio $(95 \% \mathrm{Cl})$ & $p$ value \\
\hline \multirow[t]{4}{*}{ All-causes } & Model 1 & $1.00(0.97-1.03)$ & 0.815 & $0.87(0.74-1.02)$ & 0.088 \\
\hline & Model 2 & $1.01(0.98-1.05)$ & 0.517 & $0.92(0.77-1.11)$ & 0.392 \\
\hline & Model 3 & $1.03(1.01-1.06)$ & 0.017 & $1.01(0.87-1.17)$ & 0.888 \\
\hline & Model 1 & $1.08(1.01-1.15)$ & 0.016 & $1.12(0.80-1.58)$ & 0.518 \\
\hline \multirow[t]{3}{*}{ ASCVD } & Model 2 & $1.09(1.02-1.17)$ & 0.013 & $1.14(0.78-1.66)$ & 0.501 \\
\hline & Model 3 & $1.10(1.05-1.16)$ & $<0.001$ & $1.35(1.02-1.77)$ & 0.033 \\
\hline & Model 1 & $0.99(0.95-1.02)$ & 0.477 & $0.82(0.68-0.99)$ & 0.034 \\
\hline \multirow[t]{2}{*}{ Non-ASCVD } & Model 2 & $0.99(0.96-1.03)$ & 0.686 & $0.88(0.71-1.08)$ & 0.206 \\
\hline & Model 3 & $1.01(0.98-1.05)$ & 0.409 & $0.93(0.78-1.10)$ & 0.374 \\
\hline
\end{tabular}

Model 1, in which the hazard ratios were estimated using baseline GA or HbA1c values; model 2, which used mean values of GA or HbA1c during the follow-up period; and model 3, in which GA or HbA1c values during the follow-up period were treated as time-dependent variables ASCVD atherosclerotic cardiovascular disease, GA glycated albumin, HbA1c hemoglobin A1c

Unlike previous studies [4, 9], the present study did not find a nonlinear association of GA and HbAlc with the study endpoints. This inconsistency may be due to a difference in the sample size. Indeed, the above study from Japan showed a linear mortality trend for GA; however, a sub-analysis using a larger cohort found that very low levels of GA $(<12.5 \%)$ were significantly associated with increased mortality
[9]. In the present study, the higher levels of HbAlc in the analysis treating $\mathrm{HbA} 1 \mathrm{c}$ as a time dependent variables were associated with ASCVD-related mortality; meanwhile, the lower levels at baseline were a predictor for non-ASCVD-related mortality, consistent with previous large cohort studies showing a Ushaped association between HbA1c values and allcause mortality $[4,9]$.

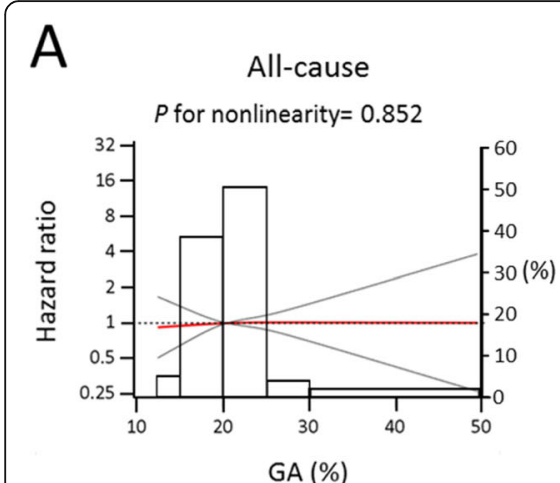

D

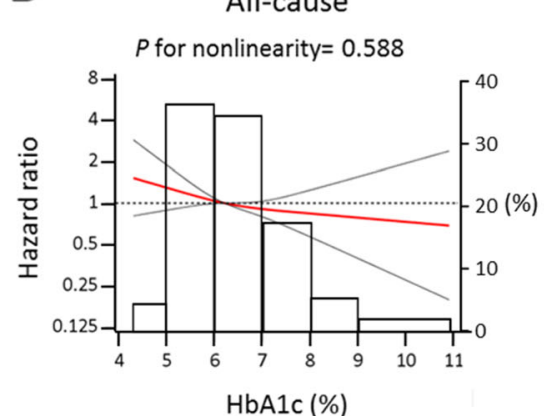

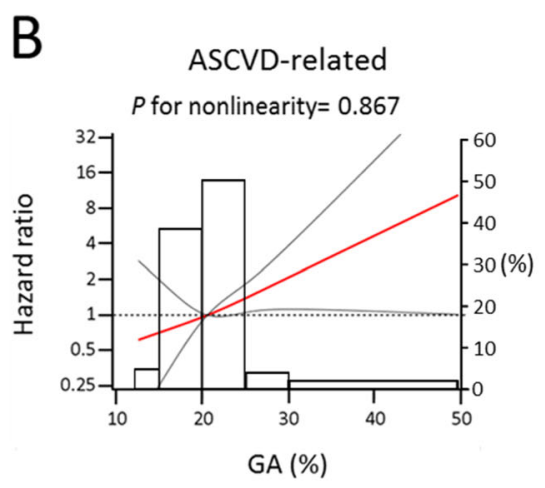

$E$

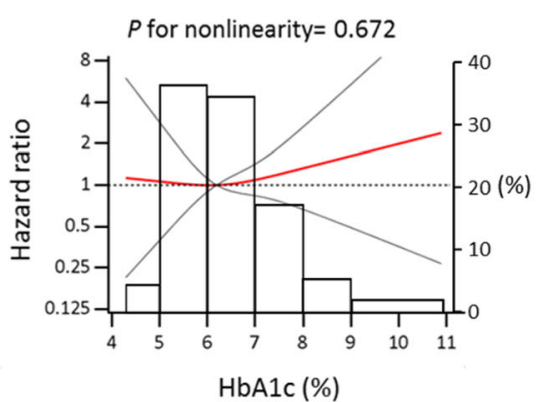

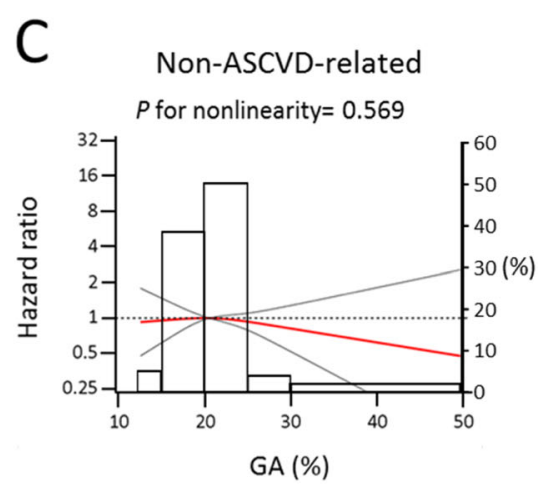

F

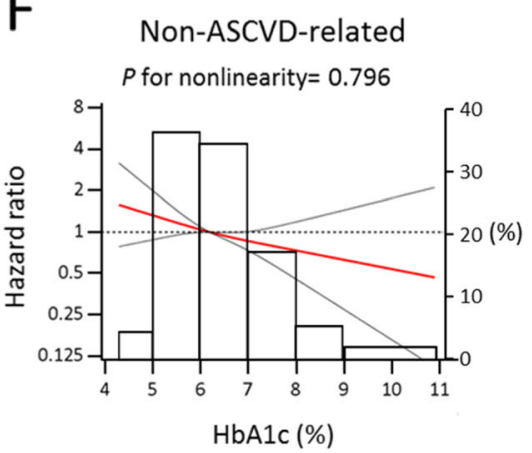

Fig. 2 Multivariable-adjusted restricted cubic spline curves ( $95 \% \mathrm{Cl}$ ) of the association between baseline GA (a-c) or $\mathrm{HbA} 1 \mathrm{c}$ levels (d-f) and each endpoint, and the histogram of GA and HbA1c levels. Reference: median of GA (20.5\%) or HbA1c (6.2\%) 
Table 3 Comparison of Uno's C-statistics for each endpoint

\begin{tabular}{|c|c|c|c|}
\hline Model 1 & $\begin{array}{l}\text { Original } \\
\text { factors }\end{array}$ & $\begin{array}{l}\text { Original factors + } \\
\text { GA }\end{array}$ & $\begin{array}{l}\text { Original factors + } \\
\mathrm{HbA1C}\end{array}$ \\
\hline All-causes & $0.718(0.024)$ & $0.718(0.020)$ & $0.720(0.019)$ \\
\hline$p$ value* & & 0.963 & 0.655 \\
\hline$p$ value ${ }^{* *}$ & & & 0.638 \\
\hline ASCVD & $0.806(0.049)$ & $0.824(0.055)$ & $0.810(0.053)$ \\
\hline$p$ value* & & 0.239 & 0.714 \\
\hline$p$ value ${ }^{* *}$ & & & 0.141 \\
\hline $\begin{array}{l}\text { Non- } \\
\text { ASCVD }\end{array}$ & $0.728(0.026)$ & $0.730(0.025)$ & $0.735(0.022)$ \\
\hline$p$ value* & & 0.622 & 0.264 \\
\hline$p$ value ${ }^{* *}$ & & & 0.279 \\
\hline Model 2 & $\begin{array}{l}\text { Original } \\
\text { factors }\end{array}$ & $\begin{array}{l}\text { Original factors + } \\
\text { GA }\end{array}$ & $\begin{array}{l}\text { Original factors + } \\
\mathrm{HbA1C}\end{array}$ \\
\hline All-causes & $0.718(0.019)$ & $0.718(0.018)$ & $0.718(0.023)$ \\
\hline$p$ value* & & 0.871 & 0.993 \\
\hline$p$ value ${ }^{* *}$ & & & 0.921 \\
\hline ASCVD & $0.806(0.061)$ & $0.817(0.049)$ & $0.809(0.073)$ \\
\hline$p$ value* & & 0.464 & 0.794 \\
\hline$p$ value ${ }^{* *}$ & & & 0.430 \\
\hline $\begin{array}{l}\text { Non- } \\
\text { ASCVD }\end{array}$ & $0.728(0.027)$ & $0.729(0.023)$ & $0.731(0.026)$ \\
\hline$p$ value* & & 0.729 & 0.480 \\
\hline$p$ value** & & & 0.595 \\
\hline
\end{tabular}

Model 1, in which the hazard ratios were estimated using baseline GA or $\mathrm{HbA1c}$ values; and model 2, which used mean values of GA or HbA1c during the follow-up period

ASCVD atherosclerotic cardiovascular disease, GA glycated albumin, HbA1C hemoglobin A1C

*vs Uno's C-statistics of original factors; **vs Uno's C-statistics of original factors plus GA

The addition of GA or HbA1c values to existing risk factors for mortality did not significantly improve predictability in the present study. Interestingly, a large cohort study of Canadian patients with diabetes reported that the increased risk of end-stage kidney disease associated with poor glycemic control was attenuated with lower kidney function [26], in spite of glycemic control being established as a major prognostic and interventional factor for early stage of DKD [1]. In light of these previous findings, together with the present study, glycemic control in patient with advanced stage of DKD has the modest or little impact on kidney function or mortality.

The present study had several limitations. First, study participants were from an ethnically homogenous population in Japan. Therefore, the generalizability of the present findings may be limited. Second, we were unable to clarify the causal relationship between GA or HbA1c and the endpoints because of the study design. Third, we did not evaluate time-dependent changes in blood pressure, BMI, medication, or laboratory data other than indicators of glycemic control. Further, we did not obtain information regarding the use of erythropoiesisstimulating agents. Fourth, we were also unable to conduct the analyses using the spline model and overall $\mathrm{C}$ statistics considering time-dependent effects of GA and HbA1c values. Fifth, we did not conduct methods encouraging to account for bias due to missing data such as multiple imputation and invers probability weighting. Finally, a considerable number of patients were transferred to a different medical institution or lost to followup, possibly biasing the present findings.

\section{Conclusions}

This multi-center, prospective cohort study provides evidence that GA may be useful compared to HbA1c for predicting all-cause and ASCVD-related mortality in Japanese chronic hemodialysis patients with diabetes. The importance of glycemic managements in this patient population should be confirmed in future randomized controlled trials targeting GA as indicators of glycemic control.

\section{Supplementary information}

Supplementary information accompanies this paper at https://doi.org/10. 1186/s41100-020-00264-1.

Additional file 1. The association of GA with the endpoints. These tables show hazard ratios of $1 \%$ increase in GA for each endpoint in sensitivity analyses. (docx 19.5KB)

Additional file 2. A flow diagram of the study population and multivariable-adjusted restricted cubic spline curves $(95 \% \mathrm{Cl})$ of the association between mean GA or $\mathrm{HbA} 1 \mathrm{c}$ levels and each endpoint. (pptx 186.8KB)

\section{Abbreviations}

ASCVD: Atherosclerotic cardiovascular disease; BMI: Body mass index; Cl: Confidence interval; DKD: Diabetic kidney disease; GA: Glycated albumin HbA1c: Hemoglobin A1c; IQR: Interquartile range; SD: Standard deviation;" VIF: Variation inflation factor

\section{Acknowledgements}

The authors thank to Yutaka Sasaki (Ohmiya Nishiguchi Clinic) and Shin Yagi (Yagi Naika Clinic) who contributed to the data collection and preparation of this work. The authors thank to Hidekazu Murata (Diabetes Center, Tokyo Women's Medical University School of Medicine) who assisted in the conduct of this work. The authors greatly thank all staff and patients who participated in the present study.

\section{Authors' contributions}

$\mathrm{KH}$ designed the protocol, contributed to data collection and preparation, analyzed all data, contributed to the interpretation of the results, and wrote the manuscript. MA, AF, HH, YH, YI, MI, TK, HK, KK, HK, MK, TK, KK, SK, IM, JM, SM, KM, JN, SN, YN, SN, TN, YN, NO, SO, SO, HO, SS, TS, TS, YS, MS, TS, HS, MT, $H T, T T, Y T, M T, H T, Y T, S T, S T, M U, I Y$, and HY contributed to the data collection and preparation and reviewed the manuscript. $Y U$ contributed to the interpretation of the results and reviewed the manuscript. TB conceived the study, designed the protocol, contributed to the data collection, contributed to the interpretation of the results, and edited the manuscript. TB is the guarantor of this work and, as such, had full access to all the data in the study and takes responsibility for the integrity of the data and the 
accuracy of the data analysis. All the authors have read and approved the final submission of the manuscript.

\section{Funding}

The present study was funded by the Kidney Foundation, Japan.

\section{Availability of data and materials}

The datasets used and/or analyzed during the presents study are available from the corresponding author on reasonable request.

\section{Ethics approval and consent to participate}

All procedures performed in the present study were in accordance with the ethical standards of the institutional research committee of Tokyo Women's Medical University School of Medicine and with the tenets of the Declaration of Helsinki of 1964 and its later versions. All patients provided written informed consent.

\section{Consent for publication}

Not applicable.

\section{Competing interests}

The authors declare that they have no competing interests.

\section{Author details}

'Diabetes Center, Tokyo Women's Medical University School of Medicine, 8-1 Kawada-cho, Shinjuku-ku, Tokyo 162-8666, Japan. ${ }^{2}$ Akamatsu Touseki Clinic, Tokyo, Japan. ${ }^{3}$ Shinbashi Naika Clinic, Tokyo, Japan. ${ }^{4}$ Our Lady of the Snow Social Medical Corporation St. Mary's Hospital, Fukuoka, Japan. ${ }^{5}$ Yamanouchi Hospital, Chiba, Japan. ${ }^{6}$ Kameido Nephrology Clinic, Tokyo, Japan. ${ }^{7}$ Yabuki Hospital, Yamagata, Japan. ${ }^{8}$ Tokorozawa Ishikawa Clinic, Saitama, Japan. ${ }^{9}$ Jyoban Hospital, Fukushima, Japan. ${ }^{10}$ Shimoochiai Clinic, City, Tokyo, Japan. ${ }^{11}$ Suda Clinic, Tokyo, Japan. ${ }^{12}$ Kawashima Hospital, Social Medical Corporation Kawashima Hospital Group, Tokushima, Japan. ${ }^{13}$ Yagi Naika Clinic, Tokyo, Japan. ${ }^{14}$ Honcho Yabuki Clinic, Yamagata, Japan.

${ }^{15}$ Saitama-Tsukinomori Clinic, Saitama, Japan. ${ }^{16}$ Shinsen-Ikebukuro Clinic, Tokyo, Japan. ${ }^{17}$ Ichiyokai Harada Hospital, Hiroshima, Japan. ${ }^{18}$ Nisshin Ekimae Clinic, Tokyo, Japan. ${ }^{19}$ Tendouonsen Yabuki Clinic, Yamagata, Japan.

${ }^{20}$ Yokohama Chuo Clinic, Kanagawa, Japan. ${ }^{21}$ Minami-cho Clinic, Saitama, Japan. ${ }^{22}$ Chibana Clinic, Okinawa, Japan. ${ }^{23}$ Nishi Clinic, Tokyo, Japan. ${ }^{24}$ Shirasagi Hospital, Osaka, Japan. ${ }^{25}$ Tokyo Ayase Kidney Clinic, Tokyo, Japan. ${ }^{26}$ Minami Ikebukuro Clinic, Tokyo, Japan. ${ }^{27}$ Credo Sato Clinic, Chiba, Japan. ${ }^{28}$ Toshima Chuo Hospital, Tokyo, Japan. ${ }^{29}$ Ohmiya Nishiguchi Clinic, Saitama, Japan. ${ }^{30}$ Suda Medical Clinic, Tokyo, Japan. ${ }^{31}$ lidabashi Suzuki Internal Medicine, Tokyo, Japan. ${ }^{32}$ Department of Nephrology Saitama Medical University, Saitama, Japan. ${ }^{33}$ Suda Naika Clinic, Tokyo, Japan. ${ }^{34}$ Hibiya Ishikawa Clinic, Tokyo, Japan. ${ }^{35}$ Bosei Shinjuku Minamiguchi Clinic, Tokyo, Japan. ${ }^{36}$ Shinjuku Ishikawa Clinic, Tokyo, Japan. ${ }^{37}$ Kokuryo Ishikawa Clinic, Tokyo, Japan. ${ }^{38}$ Shin-Nakano Dialysis Clinic, Tokyo, Japan. ${ }^{39}$ Kawagoe Ekimae Clinic, Saitama, Japan.

\section{Received: 2 August 2019 Accepted: 3 March 2020}

\section{Published online: 05 April 2020}

\section{References}

1. American Diabetes Association. Microvascular complication and foot care: standards of medical care in diabetes-2018. Diabetes Care. 2018;41(Suppl 1): S105-18.

2. Oomichi T, Emoto M, Tabata T, Morioka T, Tsujimoto Y, Tahara H, Shoji T, Nishizawa Y. Impact of glycemic control on survival of diabetic patients on chronic regular hemodialysis: a 7-year observational study. Diabetes Care. 2006;29:1496-500.

3. Hayashino Y, Fukuhara S, Akiba T, Akizawa T, Asano Y, Saito A, BraggGresham JL, Ramirez SP, Port FK, Kurokawa K. Diabetes, glycaemic control and mortality risk in patients on haemodialysis: the Japan Dialysis Outcomes and Practice Pattern Study. Diabetologia. 2007;50:1170-7.

4. Ricks J, Molnar MZ, Kovesdy CP, Shah A, Nissenson AR, Williams M, KalantarZadeh K. Glycemic control and cardiovascular mortality in hemodialysis patients with diabetes: a 6-year cohort study. Diabetes. 2012;61:708-15.

5. Inaba M, Okuno S, Kumeda Y, Yamada S, Imanishi Y, Tabata T, Okamura M, Okada S, Yamakawa T, Ishimura E, Nishizawa Y, Osaka CKD Expert Research Group. Glycated albumin is a better glycemic indicator than glycated hemoglobin values in hemodialysis patients with diabetes: effect of anemia and erythropoietin injection. J Am Soc Nephrol. 2007;18:896-903.

6. Nakao T, Inaba M, Abe M, Kaizu K, Shima K, Babazono T, Tomo T, Hirakata H, Akizawa T. Japanese Society for Dialysis Therapy. Best practice for diabetic patients on hemodialysis. Ther Apher Dial 2015. 2012;19(Suppl 1):S40-66.

7. Speeckaert M, Van Biesen W, Delanghe J, Slingerland R, Wiecek A, Heaf J, Drechsler C, Lacatus R, Vanholder R, Nistor I. European Renal Best Practice Guideline Development Group on Diabetes in Advanced CKD. Are there better alternatives than haemoglobin A1c to estimate glycaemic control in the chronic kidney disease population? Nephrol Dial Transplant. 2014;29: 2167-77.

8. Chen CW, Drechsler C, Suntharalingam P, Karumanchi SA, Wanner C, Berg $\mathrm{AH}$. High glycated albumin and mortality in persons with diabetes mellitus on hemodialysis. Clin Chem. 2017:63:477-85.

9. Hoshino J, Hamano T, Abe M, Hasegawa T, Wada A, Ubara Y, Takaichi K, Inaba M, Nakai S, Masakane I; Committee of Renal Data Registry of the Japanese Society for Dialysis Therapy. Glycated albumin versus hemoglobin A1c and mortality in diabetic hemodialysis patients: a cohort study. Nephrol Dial Transplant 2018; 33: 1150-1158.

10. Kalantar-Zadeh K, Kopple JD, Regidor DL, Jing J, Shinaberger CS, Aronovitz J, McAllister CJ, Whellan D, Sharma K. A1C and survival in maintenance hemodialysis patients. Diabetes Care. 2007;30:1049-55.

11. Koga M, Kasayama S, Kanehara H, Bando Y. CLD (chronic liver diseases)$\mathrm{HbA} 1 \mathrm{C}$ as a suitable indicator for estimation of mean plasma glucose in patients with chronic liver diseases. Diabetes Res Clin Pract. 2008;81:258-62.

12. Koga M, Murai J, Saito H, Matsumoto S, Kasayama S. Effects of thyroid hormone on serum glycated albumin levels: study on non-diabetic subjects. Diabetes Res Clin Pract. 2009;84:163-7.

13. Durrleman S, Simon R. Flexible regression models with cubic splines. Stat Med. 1989:8:551-61.

14. Uno H, Cai T, Pencina MJ, D'Agostino RB, Wei LJ. On the C-statistics for evaluating overall adequacy of risk prediction procedures with censored survival data. Stat Med. 2011;30:1105-17.

15. Hocking RR. Methods and applications of linear models. New York: Willey; 1996

16. Fine JP, Gray RJ. A proportional hazards model for the sub-distribution of a competing risk. J Am Stat Assoc. 1999;94:496-509.

17. Austin PC, Lee DS, Fine JP. Introduction to the analysis of survival data in the presence of competing risks. Circulation. 2016;133:601-9.

18. Zhang W, He J, Zhang F, Huang C, Wu Y, Han Y, Zhang W, Zhao Y. Prognostic role of C-reactive protein and interleukin- 6 in dialysis patients: a systematic review and meta-analysis. J Nephrol. 2013;26:243-53.

19. Fukuoka K, Nakao K, Morimoto H, Nakao A, Takatori Y, Arimoto K, Taki M, Wada J, Makino H. Glycated albumin levels predict long-term survival in diabetic patients undergoing haemodialysis. Nephrology. 2008;13:278-83.

20. Shafi T, Sozio SM, Plantinga LC, Jaar BG, Kim ET, Parekh RS, Steffes MW, Powe NR, Coresh J, Selvin E. Serum fructosamine and glycated albumin and risk of mortality and clinical outcomes in hemodialysis patients. Diabetes Care. 2013;36:1522-33.

21. Dekker FW, de Mutsert R, van Dijk PC, Zoccali C, Jager KJ. Survival analysis: time-dependent effects and time-varying risk factors. Kidney Int. 2008;74: 994-7.

22. Xie D, Yang W, Jepson C, Roy J, Hsu JY, Shou H, Anderson AH, Landis JR3, Feldman HI: Chronic Renal Insufficiency Cohort (CRIC) Study Investigators. Statistical methods for modeling time-updated exposures in cohort studies of chronic kidney disease. Clin J Am Soc Nephrol 2017; 12: 1892-1899.

23. Masakane I, Nakai S, Ogata S, Kimata N, Hanafusa N, Hamano T, Wakai K, Wada A, Nitta K. An Overview of regular dialysis treatment in Japan (as of 31 December 2013). Ther Apher Dial. 2015;19:540-74.

24. ANZDATA Registry Annual Report 2017, Chapter 3: Mortality in End Stage Kidney Disease. Available at: http://www.anzdata.org.au/v1/report_2017.html.

25. Saran R, Robinson B, Abbott KC, LYC A, Bhave N, Bragg-Gresham J, Balkrishnan R, Dietrich X, Eckard A, Eggers PW, Gaipov A, Gillen D, Gipson D, Hailpern SM, Hall YN, Han Y, He K, Herman W, Heung M, Hirth RA, Hutton D, Jacobsen SJ, Jin Y, Kalantar-Zadeh K, Kapke A, Kovesdy CP, Lavallee D, Leslie J, McCullough K, Modi Z, Molnar MZ, Montez-Rath M, Moradi H, Morgenstern H, Mukhopadhyay P, Nallamothu B, Nguyen DV, Norris KC, O'Hare AM, Obi Y, Park C, Pearson J, Pisoni R, Potukuchi PK, Rao P, Repeck K, Rhee CM, Schrager J, Schaubel DE, Selewski DT, Shaw SF, Shi JM, Shieu M, Sim JJ, Soohoo M, Steffick D, Streja E, Sumida K, Tamura MK, Tilea A, Tong L, Wang D, Wang M, Woodside KJ, Xin X, Yin M, You AS, Zhou H, Shahinian V. 
US renal data system 2017 annual data report: epidemiology of kidney disease in the United States. Am J Kindy Dis. 2018;71(Suppl 1):S1-S672.

26. Shurraw S, Hemmelgarn B, Lin M, Majumdar SR, Klarenbach S, Manns B, Bello A, James M, Turin TC, Tonelli M. for the Alberta Kidney Disease

Network. Association between glycemic control and adverse outcomes in people with diabetes mellitus and chronic kidney disease. Arch Intern Med. 2011;171:1920-7.

\section{Publisher's Note}

Springer Nature remains neutral with regard to jurisdictional claims in published maps and institutional affiliations.

Ready to submit your research? Choose BMC and benefit from:

- fast, convenient online submission

- thorough peer review by experienced researchers in your field

- rapid publication on acceptance

- support for research data, including large and complex data types

- gold Open Access which fosters wider collaboration and increased citations

- maximum visibility for your research: over $100 \mathrm{M}$ website views per year

At $\mathrm{BMC}$, research is always in progress.

Learn more biomedcentral.com/submissions 